\title{
Posters Presentation on Breast Feeding, Mother Cancer Awareness, Mother and Child Health, Mother Healthy Food and Mother Mental Health
}

\section{Dr Ahsan Ali Siddiqui MD, MSPH (UK)*}

Quality Management \& Patient Safety Department, General Directorate of Health, Riyadh Saudi Arabia

*Corresponding author: Dr Ahsan Ali Siddiqui, Consultant Epidemiologist, Quality Management and Patient Safety Department MOH Riyadh Saudi Arabia, Email: drahsan77@hotmail.com

\section{ARTICLE INFO}

Received: 㗀 February 25, 2019

Published: March 06, 2019

Citation: Dr Ahsan Ali Siddiqui. Posters Presentation on Breast Feeding, Mother Cancer Awareness, Mother and Child Health, Mother Healthy Food and Mother Mental Health. Biomed J Sci \& Tech Res 15(3)-2019. BJSTR. MS.ID.002717.

\section{ABSTRACT}

The Idea is to Present and Collect Number of Five Posters on the following Topics mentioned below in one Article to be Prepared and published for Research Purposes.

Keywords: Breast Feeding; Mother Cancer Awareness; Mother and Child Health; Mother Healthy Food; Mother Mental Health (Figures 1-5)

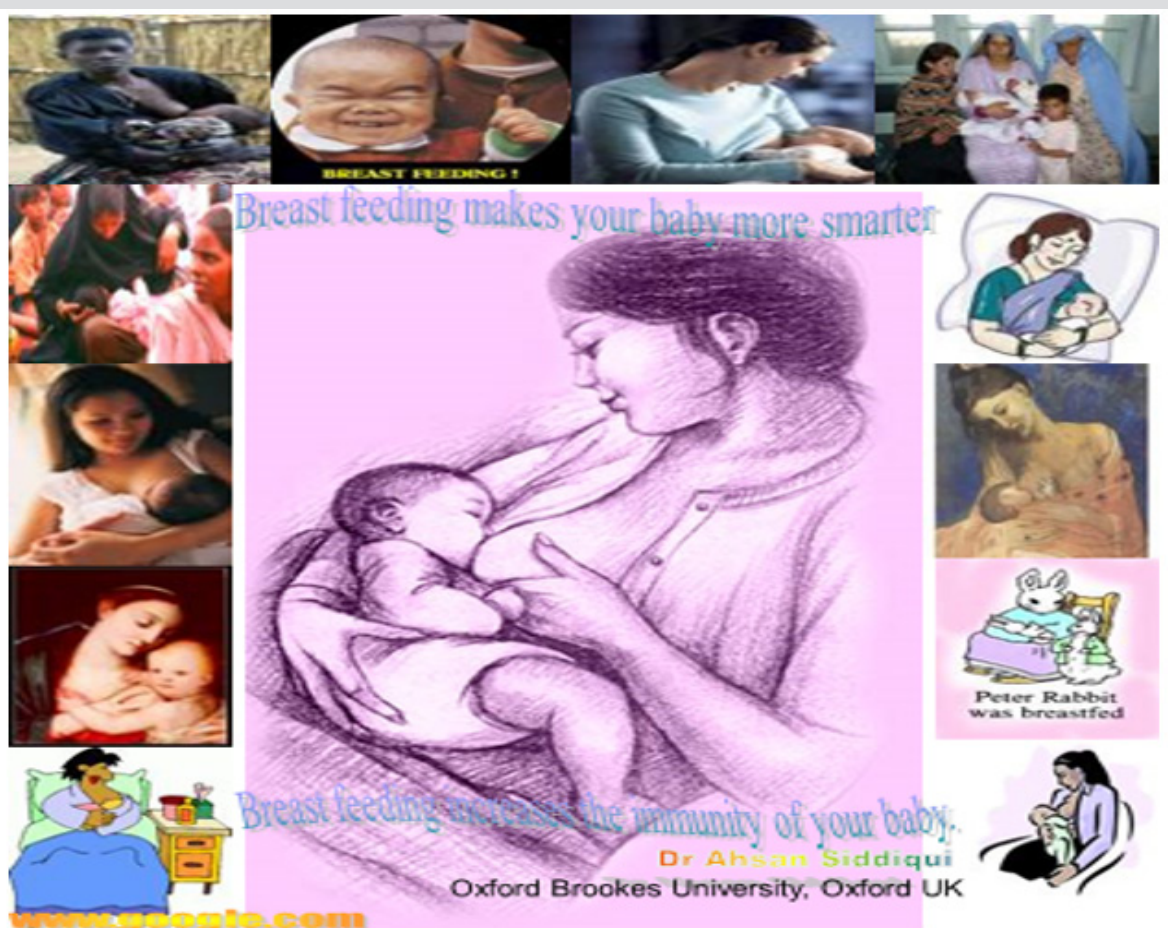

Figure 1: Poster Breast Feeding and its Advantages. 


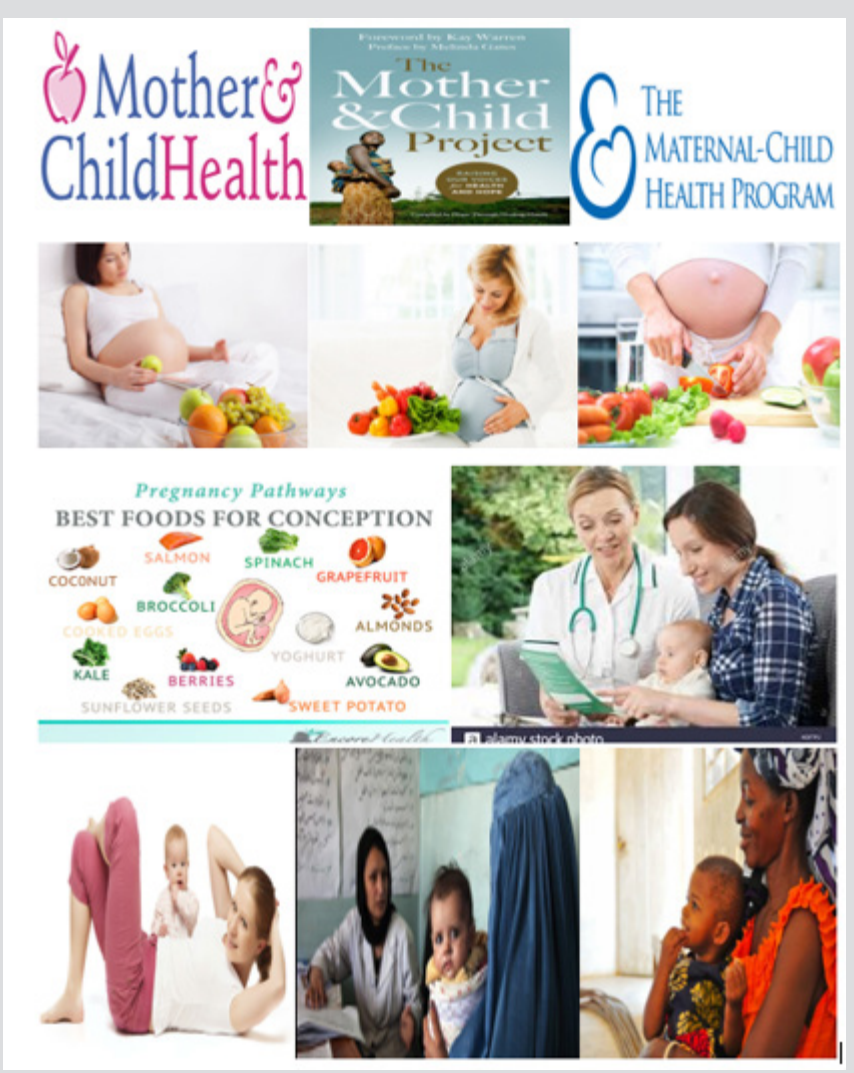

Figure 2: Poster on Mother and Child Health.

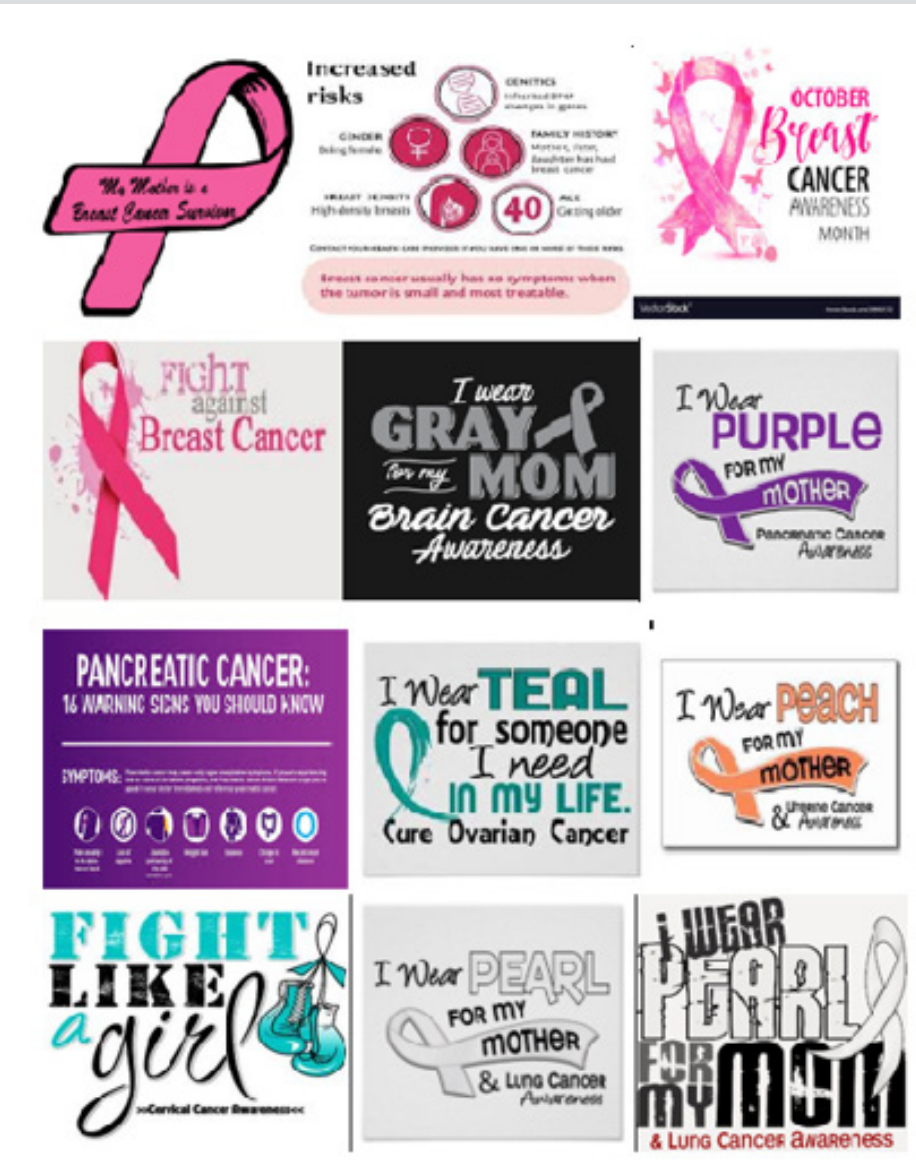

Figure 3: Poster on Mother Cancer Awareness. 

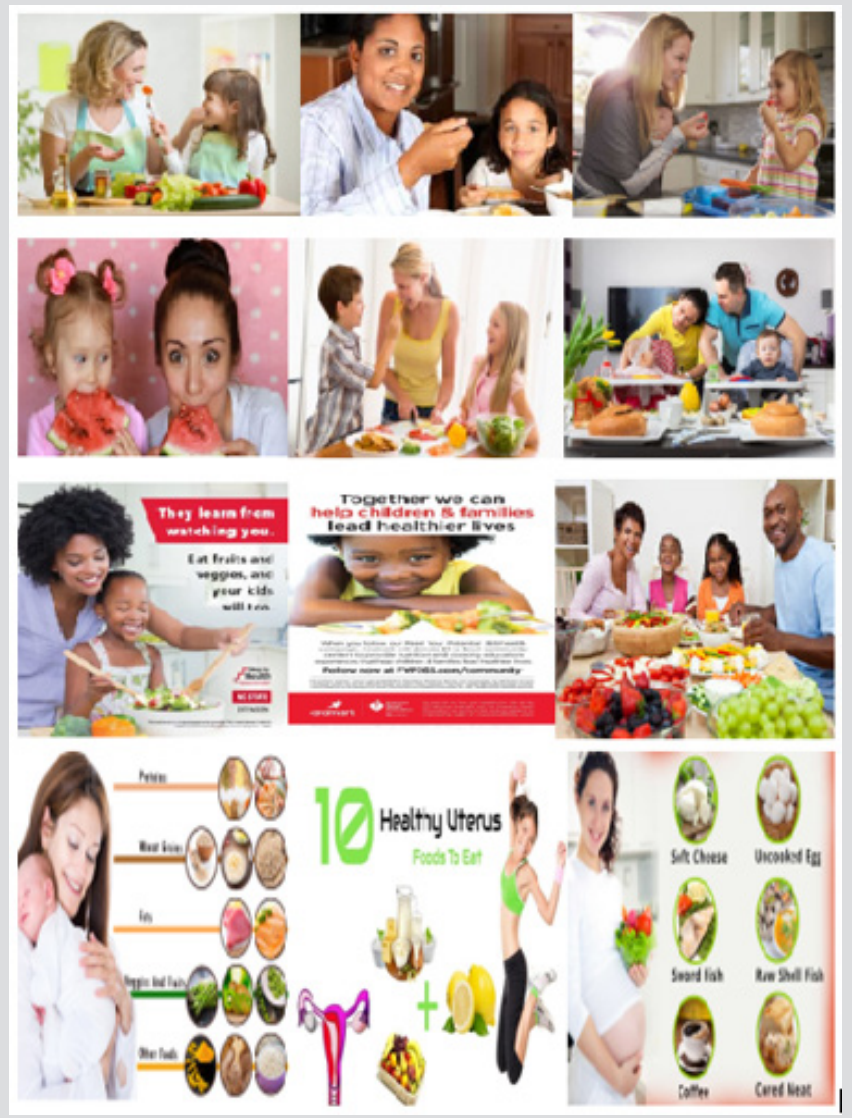

Figure 4: Poster on Mother Healthy Food.
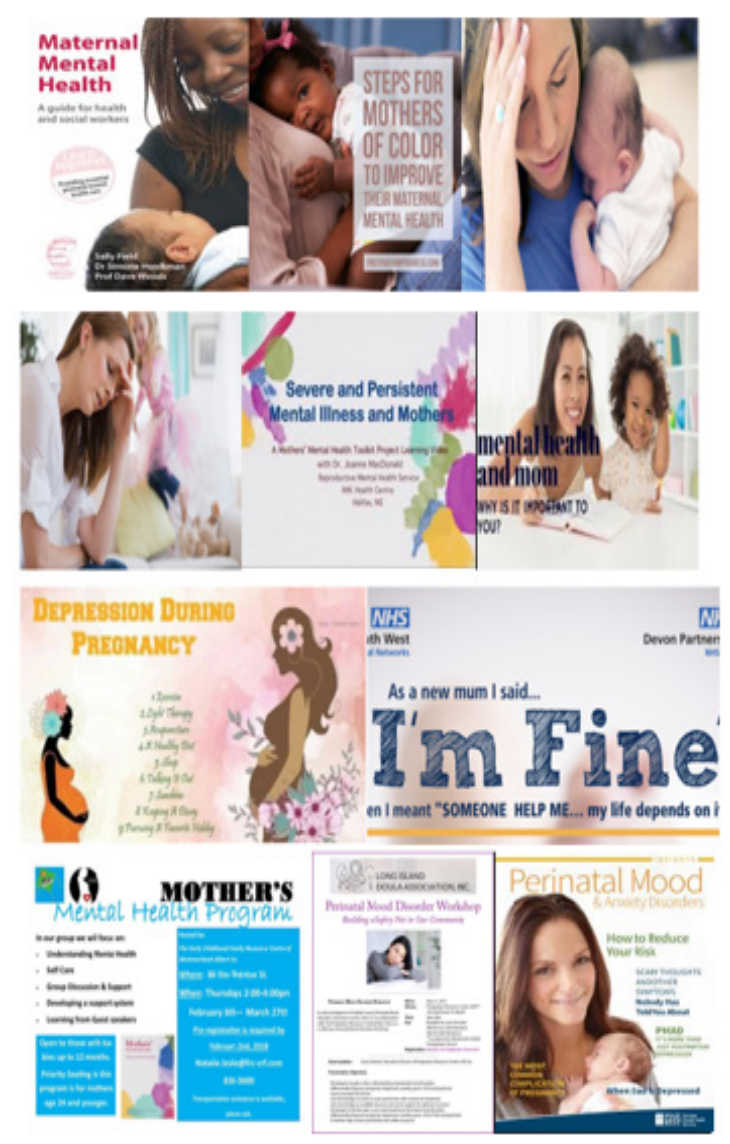

Figure 5: Poster on Mother Mental Health. 


\section{ISSN: 2574-1241}

DOI: 10.26717/BJSTR.2019.15.002717

Dr Ahsan Ali Siddiqui. Biomed J Sci \& Tech Res

(C) (P) This work is licensed under Creative

Submission Link: https://biomedres.us/submit-manuscript.php

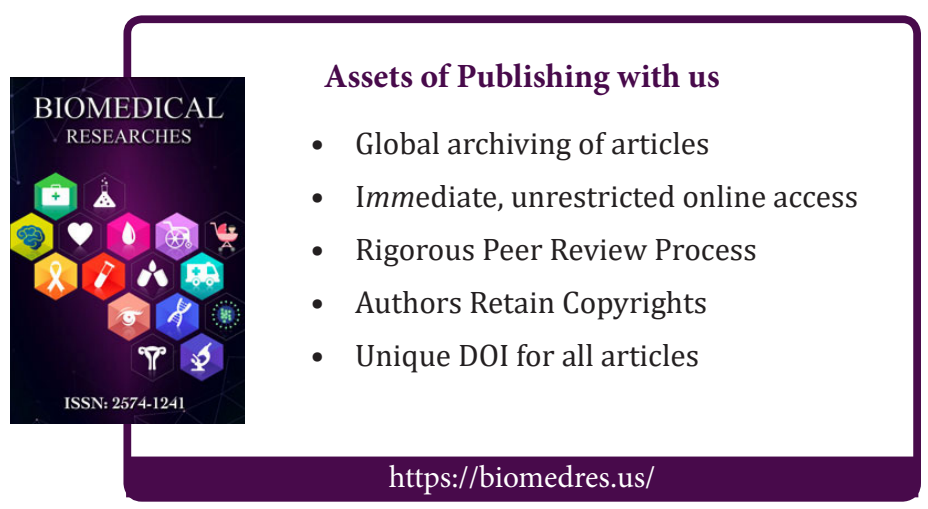

